ARTICLE

https://doi.org/10.1038/s41467-019-11439-8

\title{
Overlooked electrolyte destabilization by manganese (II) in lithium-ion batteries
}

Cun Wang ${ }^{1,3}$, Lidan Xing ${ }^{1,3}$, Jenel Vatamanu ${ }^{2}$, Zhi Chen ${ }^{1}$, Guangyuan Lan ${ }^{1}$, Weishan Li $^{1}$ \& Kang Xu ${ }^{2}$

Transition-metal dissolution from cathode materials, manganese in particular, has been held responsible for severe capacity fading in lithium-ion batteries, with the deposition of the transition-metal cations on anode surface, in elemental form or as chelated-complexes, as the main contributor for such degradations. In this work we demonstrate with diverse experiments and calculations that, besides interfacial manganese species on anode, manganese(II) in bulk electrolyte also significantly destabilizes electrolyte components with its unique solvation-sheath structure, where the decompositions of carbonate molecules and hexafluorophosphate anion are catalyzed via their interactions with manganese(II). The manganese(II)-species eventually deposited on anode surface resists reduction to its elemental form because of its lower electrophilicity than carbonate molecule or anion, whose destabilization leads to sustained consumption. The reveal understanding of the once-overlooked role of manganese-dissolution in electrolytes provides fresh insight into the failure mechanism of manganese-based cathode chemistries, which serves as better guideline to electrolyte design for future batteries.

\footnotetext{
${ }^{1}$ National and Local Joint Engineering Research Center of MPTES in High Energy and Safety LIBs, Engineering Research Center of MTEES (Ministry of Education), and Key Lab. of ETESPG(GHEI), South China Normal University, 510006 Guangzhou, China. ${ }^{2}$ Electrochemistry Branch, Sensor and Electron Devices Directorate, Power and Energy Division, U.S. Army Research Laboratory, Adelphi, MD 20783, USA. ${ }^{3}$ These authors contributed equally: Cun Wang, Lidan Xing. Correspondence and requests for materials should be addressed to L.X. (email: xingld@scnu.edu.cn) or to K.X. (email: conrad.k.xu.civ@mail.mil)
} 
$\mathrm{M}$ anganese-rich (Mn-rich) cathode chemistries attract persistent attention due to pressing needs to reduce the reliance on cobalt in lithium-ion batteries (LIBs) $)^{1,2}$. Recently, a disordered rocksalt material with reversible $\mathrm{Mn}^{2}$ ${ }^{+} / \mathrm{Mn}^{4+}$ redox-pairs was proposed, promising extremely high capacity of $>300 \mathrm{mAh} \mathrm{g}^{-1}$ and energy density of $\sim 1000 \mathrm{Wh} \mathrm{kg}^{-1}$. Such new materials created opportunities for the next generation LIBs, but will inevitably encounter the decade-long challenge of $\mathrm{Mn}^{2+}$-dissolution in electrolytes, which has prevented the application of almost all Mn-rich materials ${ }^{3}$. Dissolution of transition-metal (TM) ions is closely associated with battery performance-degradation ${ }^{4-11}$, the accepted mechanism behind which has been overwhelmingly focused on interfacial TMspecies on anode surface, resulting from dissolved TM-ions migrating from cathode and eventually depositing, in either elemental form or chelated TM-complexes, as part of the solidelectrolyte-interphase (SEI) on anode ${ }^{12-17}$. However, the role of soluble $\mathrm{Mn}^{2+}$-species in bulk electrolytes has been completely overlooked thus far. Given the continuous $\mathrm{Mn}^{2+}$-dissolution and its slow migration to the anode surface, $\mathrm{Mn}^{2+}$-species should accumulate to sufficiently high concentrations in bulk electrolyte, and it is of high interest to understand how the bivalent $\mathrm{Mn}^{2+}$ as a rival cation of $\mathrm{Li}^{+}$competes for the solvation from both carbonate and anion. As established earlier by $\mathrm{Xu}$ and coworkers that $\mathrm{Li}^{+}$-solvation directly dictates interphasial chemistries in LIBs ${ }^{18,19}$, the competitive solvation between $\mathrm{Li}^{+}$and $\mathrm{Mn}^{2+}$ should never be under-estimated.

Here in this work, using computation, spectroscopic, and electrochemical characterizations, we identify the dissolved $\mathrm{Mn}^{2+}$ as catalytic center that induce continuous electrolyte consumption at the expense of the cell performances. In comparison with $\mathrm{Li}^{+}$, the bivalent $\mathrm{Mn}^{2+}$ forms larger solvation sheath containing both $\mathrm{PF}_{6}{ }^{-}$and carbonate molecules, wherein $\mathrm{Mn}^{2+}$ readily activates these solvation members either for side reactions in the bulk electrolyte or for electrochemical reductions at anode surface. This destabilization becomes overwhelming at elevated temperatures, leading to significant change in both bulk electrolyte composition and interphasial chemistry. Such precise understanding of how soluble Mn-species affect battery performance constitutes critical knowledge to enable these Mn-rich cathode chemistries.

\section{Results}

$\mathrm{Mn}^{2+}$-solvation structure in carbonate-based electrolyte. The ability of $\mathrm{Mn}^{2+}$ to compete for the solvation from carbonate solvents and anions and the resultant solvation sheath structure were calculated by density function theory (DFT) (Supplementary Fig. 1), in comparison with the interacting structures and energy of $\mathrm{Li}^{+}$. The calculated interaction energies of $\mathrm{Mn}^{2+}$ with ethylene carbonate (EC), dimethyl carbonate (DMC), ethyl methyl carbonate (EMC), diethyl carbonate (DEC), $\mathrm{PF}_{6}^{-}$, and bis(trifluoromethane sulfonyl)imide $\left(\mathrm{TFSI}^{-}\right.$) are $-51.11,-41.49$, $-43.17,-43.97,-45.39$, and -72.37 (with $\mathrm{O}$ in $\mathrm{TFSI}^{-}$) $\mathrm{kJ} \mathrm{mol}^{-1}$, respectively. Here $\mathrm{TFSI}^{-}$, which does not contain chemically labile fluorine bonds and is intrinsically non-acidic, was used as a reference with the acidic anion $\mathrm{PF}_{6}-$ typically used in state-of-the-art electrolytes.

The interaction energies of $\mathrm{Mn}^{2+}$ are found to be constantly higher (more negative) than those of $\mathrm{Li}^{+}$, which unambiguously indicate that the bivalent cation $\mathrm{Mn}^{2+}$ enjoys the privilege of being solvated by carbonate molecules or anions in competition with $\mathrm{Li}^{+}$(Supplementary Fig. 1). Equally important is the preference of EC and $\mathrm{TFSI}^{-}$by $\mathrm{Mn}^{2+}$ over the other investigated carbonate solvents (DMC, EMC, and DEC) and $\mathrm{PF}^{-}$anion. A $\mathrm{Mn}^{2+}$-solvation sheath at equilibrium, therefore, should be mainly populated by EC and $\mathrm{TFSI}^{-}$. Indeed, differing from $\mathrm{Li}^{+}$ (Fig. 1a), the radial distribution function obtained from molecular dynamic (MD) simulation reveals that the first solvation shell of $\mathrm{Mn}^{2+}$ is dominated by carbonyl $\mathrm{O}$ in EC, $\mathrm{O}$ in $\mathrm{TFSI}^{-}$, and to a much lesser extent by $\mathrm{F}$ in $\mathrm{PF}_{6}^{-}$and carbonyl $\mathrm{O}$ in $\mathrm{DMC}$ (Fig. 1b). Due to its higher charge density and roughly the same ionic radius ( +2 and $80 \mathrm{pm}$ for $\mathrm{Mn}^{2+}$ vs. +1 and $90 \mathrm{pm}$ for $\mathrm{Li}^{+}$), $\mathrm{Mn}^{2+}$ requires higher solvation number than $\mathrm{Li}^{+}$in order to remain soluble, hence its first solvation sheath is larger than $\mathrm{Li}^{+}$ as identified from MD simulations (Fig. 1c, d). It is worth mentioning that DFT calculations and MD simulations respectively identified $\mathrm{N}$ (Supplementary Fig. 1) or O (Fig. 1b, c) in TFSI $^{-}$as the main solvating site for $\mathrm{Mn}^{2+}$. MD simulation should be closer to reality, because with lower steric hindrance, $\mathrm{O}$ in TFSI $^{-}$is expected to be more accessible to $\mathrm{Mn}^{2+}$, which in turn generates a larger solvation sheath.

As TFSI $^{-}$is not a typical salt anion used in most commercial electrolytes and only introduced as a non-acidic anion reference to evaluate the decomposition effect of $\mathrm{PF}_{6}{ }^{-}$, how $\mathrm{PF}_{6}{ }^{-}$and $\mathrm{EC}$ interact with $\mathrm{Mn}^{2+}$ is of primary interest. Surprisingly, the length of $\mathrm{F}^{-} \mathrm{P}$ bond in $\mathrm{PF}_{6}{ }^{-}$increases from 1.62 to $1.77 \AA$ (Supplementary Fig. 1) when interacting with $\mathrm{Mn}^{2+}$, as compared with $1.68 \AA$ when interacting with $\mathrm{Li}^{+}$. Similar trend can also be obtained from MD simulations (Supplementary Fig. 2a), suggesting that $\mathrm{Mn}^{2+}$-dissolution into $\mathrm{PF}_{6}{ }^{-}$-containing electrolyte would result in $\mathrm{Mn}^{2+}$-solvation sheaths where $\mathrm{PF}_{6}{ }^{-}$anion becomes rather activated as indicated by the longer P-F bond. The torn-apart $\mathrm{PF}_{6}{ }^{-}$subsequently generates $\mathrm{PF}_{5}$, an especially strong Lewis acid, which has been known to trigger a series of carbonate molecule decompositions ${ }^{20}$. In the reaction profile of EC (Supplementary Fig. 2b), the presence of $\mathrm{PF}_{5}$ greatly reduces the decomposition energy barrier by $39 \mathrm{~kJ} \mathrm{~mol}^{-1}$. Such catalytic effect would be exponentially accelerated at elevated temperatures.

Influence of dissolved $\mathrm{Mn}^{2+}$ on electrolyte thermostability. Experiments firmly support the above theoretical calculation regarding the unique solvation sheath structure of $\mathrm{Mn}^{2+}$ and how this structure destabilizes electrolyte components. Electrolytes containing both $\mathrm{Li}^{+}$and $\mathrm{Mn}^{2+}$ cations with $\mathrm{PF}_{6}{ }^{-}$and TFSI ${ }^{-}$ anions were prepared and labeled Electrolytes 1 through 6 (Fig. 2a, b, and Supplementary Table 1), which were then subject to storage at $55^{\circ} \mathrm{C}$ for 8 days, so that potential side reactions are accelerated in a visible manner. The color of $\mathrm{LiPF}_{6}$-free electrolytes (Fig. 2a, b, Electrolytes 1, 3, and 4) remain unchanged after such storage, indicating that neither $\mathrm{Li}^{+}, \mathrm{Mn}^{2+}$ nor $\mathrm{TFSI}^{-}$will induce drastic decomposition. Under the same condition, the two electrolytes containing $\mathrm{LiPF}_{6}$ (Electrolytes 2 and 5) discolor slightly, identifying $\mathrm{PF}_{6}-$ as the source that induces the side reactions of carbonate-based electrolyte to a moderate extent ${ }^{21,22}$, perhaps via the trace presence of $\mathrm{PF}_{5}$. In sharp contrast, significant color-change occurred when $\mathrm{Mn}^{2+}$ and $\mathrm{PF}_{6}-$ coexist (Electrolyte 6), which directly confirms the destabilization of the electrolyte via the cooperation of both $\mathrm{Mn}^{2+}$ and $\mathrm{PF}_{6}{ }^{-}$. The measured average $\mathrm{H}_{2} \mathrm{O}$ content for Electrolytes 1, 2, 3, 4, 5, and 6 before storage is $21,24,65,70,68$, and $72 \mathrm{ppm}$, respectively. The TFSI-containing electrolytes (Electrolytes 4, 5, and 6) show higher moisture than the others due to the commercial TFSI-salts (both $\mathrm{Li}^{+}$and $\mathrm{Mn}^{2+}$ ) which were synthesized via aqueous routes, and whose moisture level has always been an issue. However, it should be noted that the discoloration of Electrolyte 6 (containing combination $\left.\mathrm{LiPF}_{6} / \mathrm{Mn}(\mathrm{TFSI})_{2}\right)$ is significantly more obvious than both Electrolytes 4 and 5 (containing either $\mathrm{Mn}(\mathrm{TFSI})_{2}$ alone or combination of $\mathrm{LiPF}_{6}$ /LiTFSI; Fig. 2b), despite their $\mathrm{H}_{2} \mathrm{O}$ contents being essentially the same within experimental error. This clear distinction decouples the discoloration of Electrolyte 6 

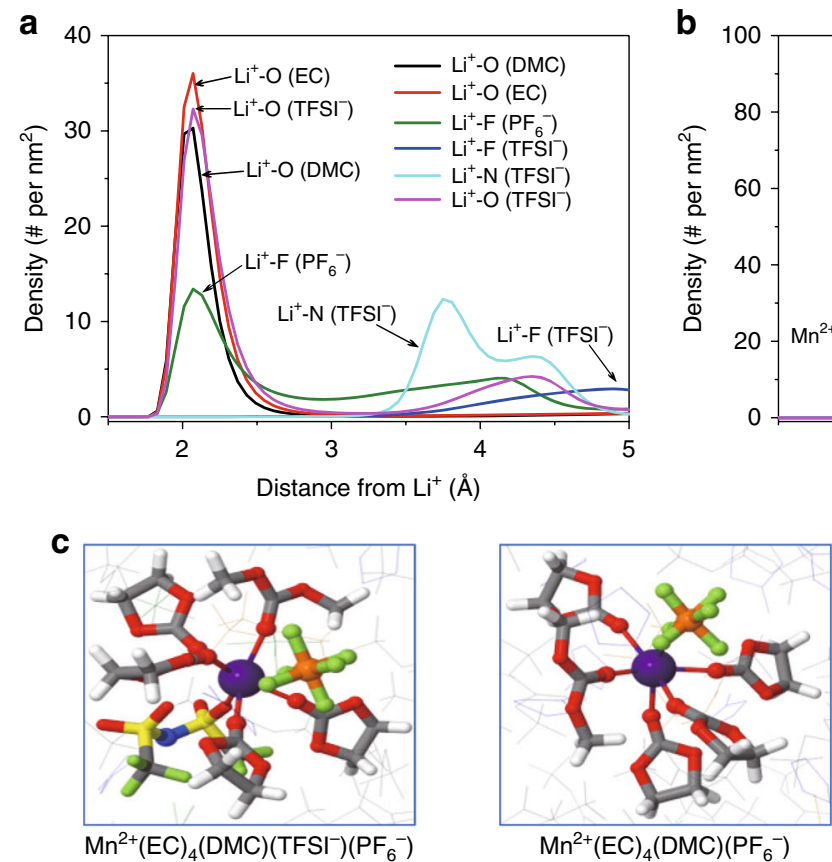

$\mathrm{Mn}^{2+}(\mathrm{EC})_{4}(\mathrm{DMC})\left(\mathrm{PF}_{6}{ }^{-}\right)$

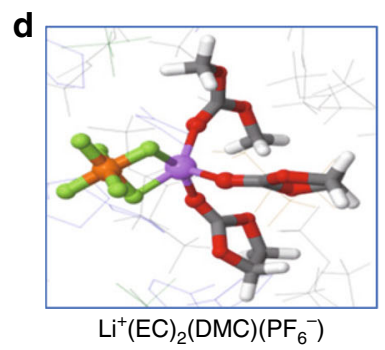

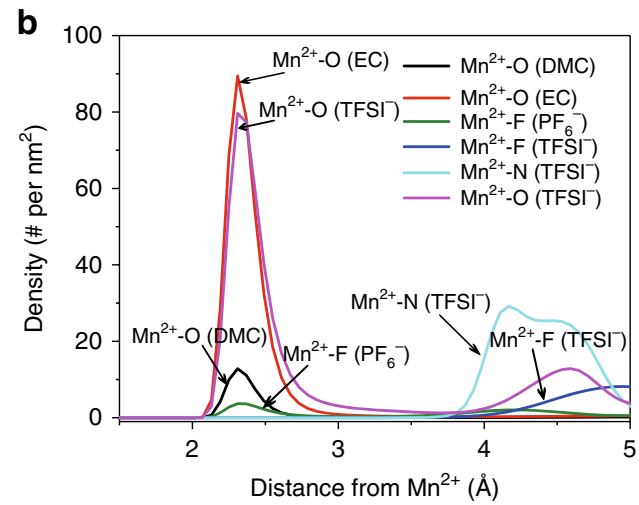

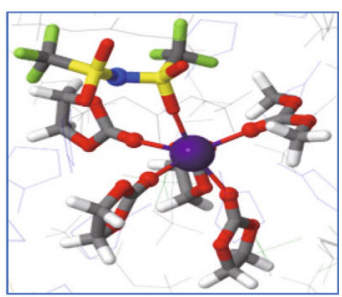

$\mathrm{Mn}^{2+}(\mathrm{EC})_{5}\left(\mathrm{TFSI}^{-}\right)$

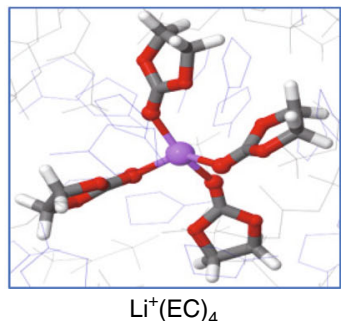

Fig. 1 Electrolyte structures obtained from molecular dynamic simulation. Radial distribution function for Li+ (a) and Mn ${ }^{2+}$ (b) in electrolytes; The typical

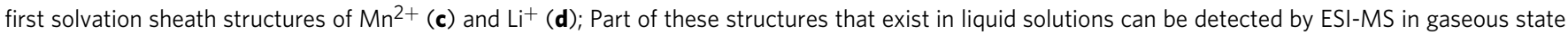
after partial desolvation of the cations

from moisture content, and strongly suggests that the electrolyte degradation of number 6 should be ascribed to the catalytic effect of $\mathrm{Mn}^{2+}$ and its interaction with $\mathrm{PF}_{6}{ }^{-}$anion. To further validate this conclusion, $1000 \mathrm{ppm} \mathrm{HF}$ was injected into electrolytes and then stored at $55^{\circ} \mathrm{C}$ for 8 days (Supplementary Fig. 3). The HF injection caused obvious discoloration as compared with the electrolyte without $\mathrm{HF}$ injection (Fig. 2b), indicating that $\mathrm{HF}$ indeed also causes electrolyte decomposition. However, the discoloration trend after storage (Supplementary Fig. 3) remains the same with that shown in Fig. 2b, with Electrolyte 6 being the most severe. This further confirms that the decomposition of Electrolyte 6 is firmly correlated with the co-existence of $\mathrm{Mn}^{2+}$ and $\mathrm{PF}_{6}{ }^{-}$.

Electrospray ionization mass spectrometry (ESI-MS) was used to map the solvation sheath structures of both $\mathrm{Li}^{+}$and $\mathrm{Mn}^{2+}$. While established earlier as a precise and quantitative tool that reveals the distribution of solvent molecules around $\mathrm{Li}^{+}$, it should be cautioned that the cation complexes as detected by ESI-MS in gaseous state actually already experienced partial desolvation during the flight under electric field, therefore, these charged species do not directly reflect the exact solvation sheaths in electrolyte solution. However, they do represent the most stable solvation species that should occur in the electrolyte solution ${ }^{18}$. It is apparent that in electrolyte containing only $\mathrm{Li}$ salts (Electrolyte 5 ), $\mathrm{Li}^{+}$is preferentially solvated by EC molecules (Fig. 2c), as evidenced by the pronounced peaks at mass-charge ratios (m/e) of 95, 127, 183, and 358 that correspond to $[\mathrm{Li}(\mathrm{EC})]^{+},[\mathrm{Li}(\mathrm{MeOH})(\mathrm{EC})]^{+},[\mathrm{Li}$ $\left.(\mathrm{EC})_{2}\right]^{+}$, and $\left[\mathrm{Li}(\mathrm{EC})_{4}\right]^{+}$, respectively, despite that EC and DMC coexist at almost equimolar ratio $(\mathrm{EC} / \mathrm{DMC}=1.02)$. Methanol $(\mathrm{MeOH})$ was used as diluent solvent in the ESI-MS experiments, hence solvation sheaths containing $\mathrm{MeOH}$ also persistently appears, showing that $\mathrm{MeOH}$ is a strong competitor against EC in solvating $\mathrm{Li}^{+}$. After this electrolyte underwent thermal storage, its ESI-MS still maintained a rather clean spectrum with almost identical patterns of these same solvation species (Fig. $2 c, d$ ), confirming the essential stability of electrolyte when $\mathrm{PF}_{6}{ }^{-}$was the only anion therein.

On the other hand, upon addition of $\mathrm{Mn}^{2+}$, a host of new species immediately appeared even before high temperature storage (Fig. 2e), as evidenced by the rather noisy background. Although it is difficult to identify all these new species, which are apparently the directly result from the electrolyte decomposition catalyzed by $\mathrm{Mn}^{2+}$ at room temperature, it is beyond doubt that extensive and chaotic reactions already occurred. Closer examination reveals that, aside from a few $\mathrm{Li}^{+}$species $(\mathrm{m} / \mathrm{e} 95,127$, 183), $\mathrm{Mn}^{2+}$-solvation species now exist, such as [Mn $\left.(\mathrm{EC})_{3}(\mathrm{MeOH})\right]^{2+}(\mathrm{m} / \mathrm{e} 175.3), \quad\left[\mathrm{Mn}(\mathrm{EC})(\mathrm{DMC})(\mathrm{MeOH})_{4}\right]^{2+}$ $(\mathrm{m} / \mathrm{e} 180.5)$, and $\left[\mathrm{Mn}(\mathrm{EC})_{4}\right]^{2+}(\mathrm{m} / \mathrm{e} 203.4)$ TFSI $^{-}$can also be observed in $\mathrm{Mn}^{2+}$-solvation as [MnTFSI $\left.(\mathrm{MeOH})_{3}\right]^{+}(\mathrm{m} / \mathrm{e} 431)$ and $\left[\mathrm{MnTFSI}(\mathrm{EC})(\mathrm{MeOH})_{2}\right]^{+}(\mathrm{m} / \mathrm{e} 487)$, whose presence, despite the low relative abundances, offers a firm support for the simulation result that $\mathrm{TFSI}^{-}$anion is preferred by $\mathrm{Mn}^{2+}$. On the other hand, no $\mathrm{Mn}^{2+}$-solvation sheaths that contain $\mathrm{PF}_{6}{ }^{-}$ anion can be detected in Fig. 2e, consistent with the calculation results $\mathrm{PF}_{6}^{-}$in $\mathrm{Mn}^{2+}$-solvation sheath will be destabilized, 
a
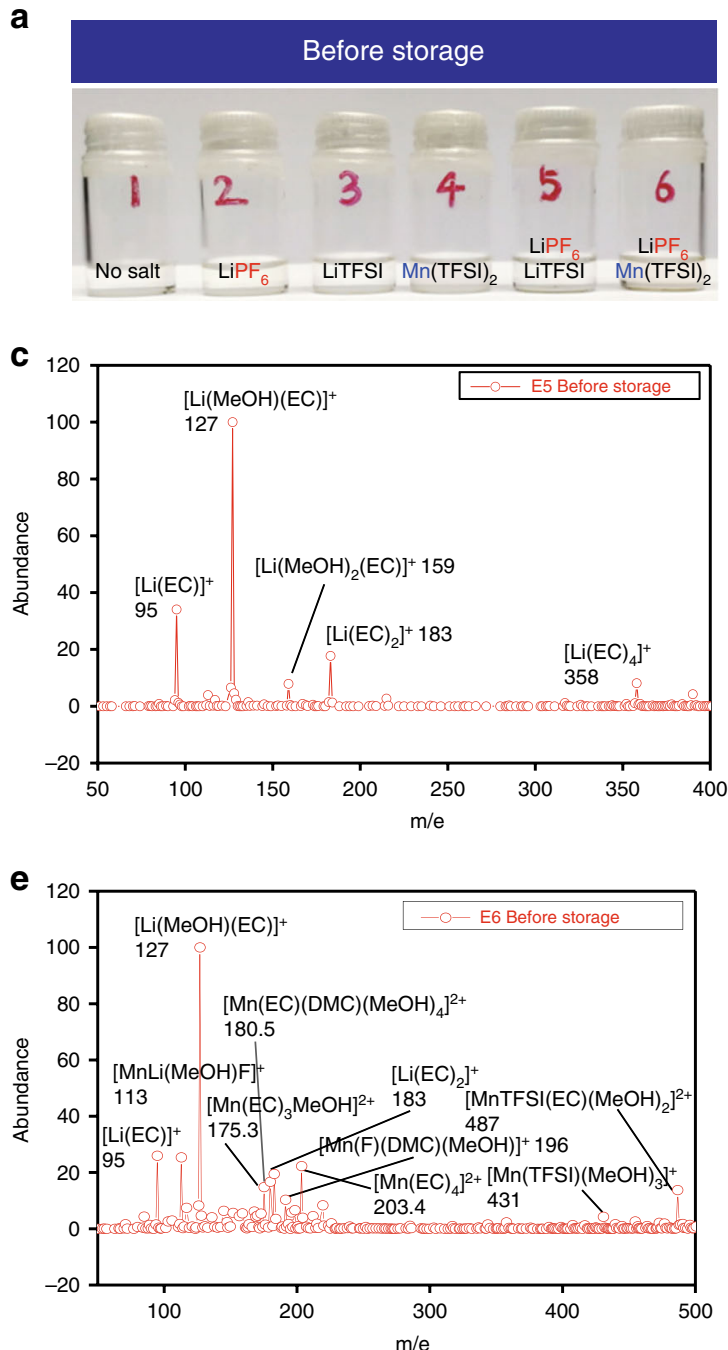

g
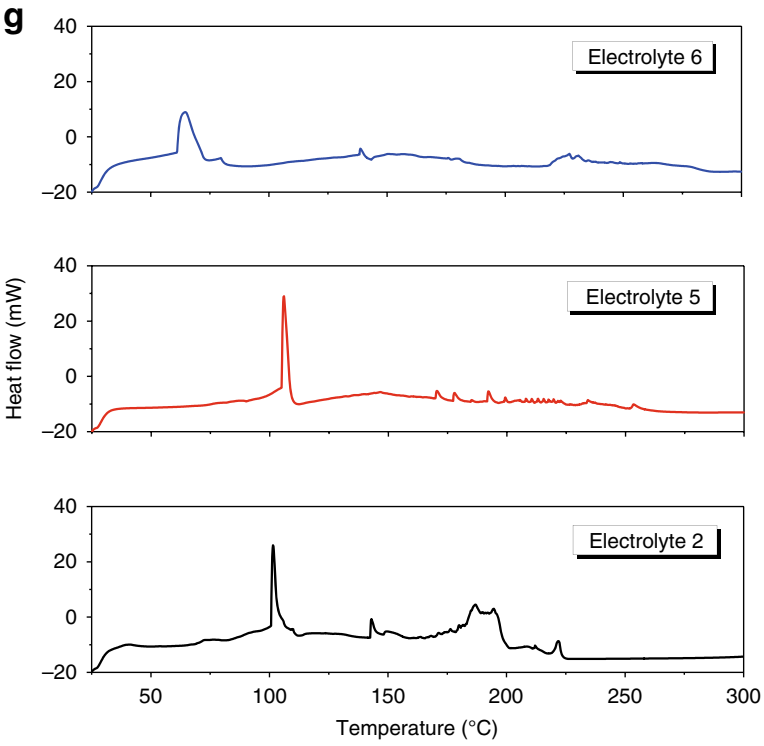

b
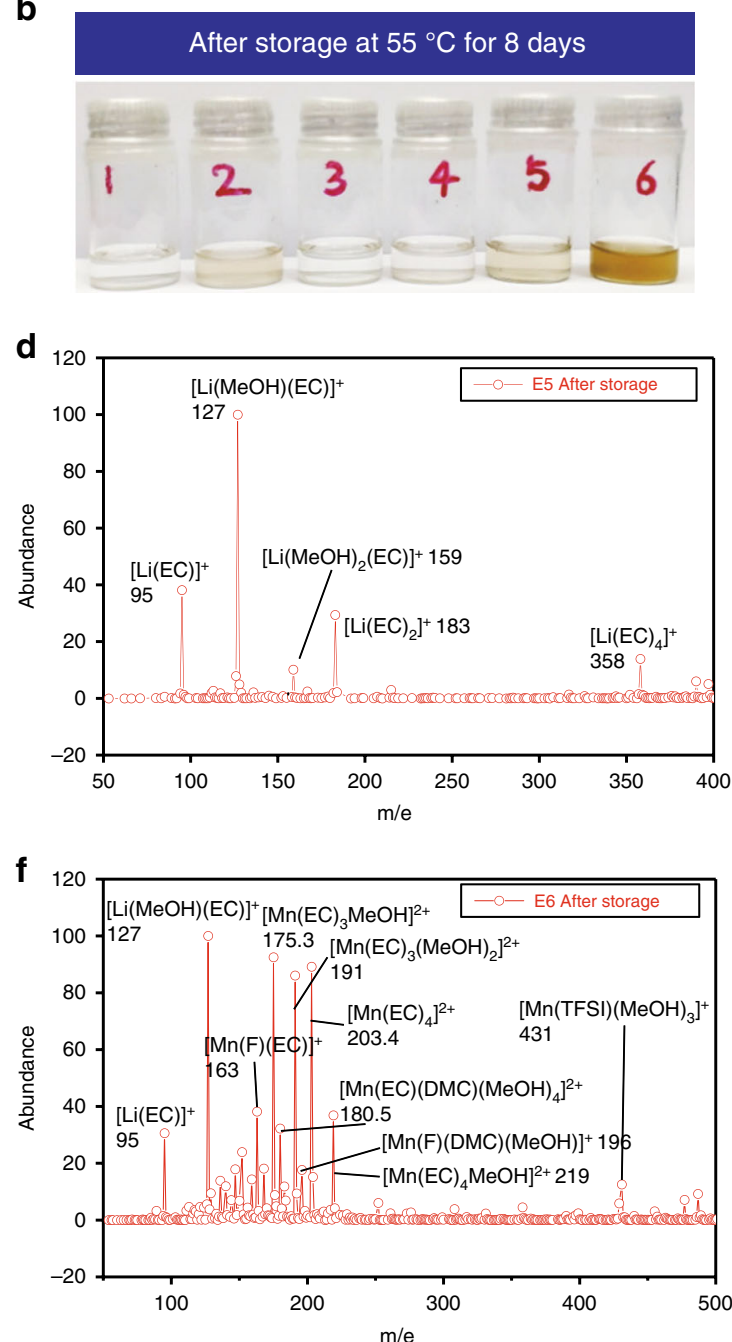

h

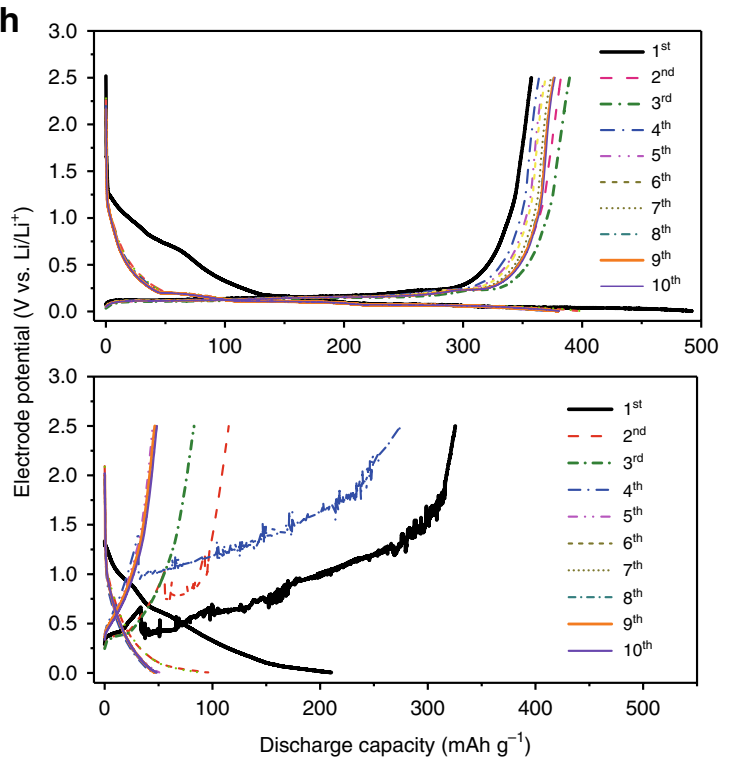

Fig. 2 Presence of $\mathrm{Mn}^{2+}$ ions triggers thermal decomposition of electrolyte. Electrolyte discoloration before (a) and after (b) storage at $55^{\circ} \mathrm{C}$ for 8 days; ESI-MS characterizations of Electrolytes 5 and 6 before $(\mathbf{c}, \mathbf{e})$ and after $(\mathbf{d}, \mathbf{f})$ storage, where methanol was used as diluent solvent; DSC curves of fresh Electrolytes 2, 5, and 6 (g); charge/discharge voltage profiles of graphite/Li half-cells containing Electrolyte 6 before (upper, $\mathbf{h}$ ) and after thermal storage (lower, $\mathbf{h}$ ) at a current density of $74.5 \mathrm{mAhg}^{-1}\left(0.2 \mathrm{C}\right.$ ) between 0.005 to $2.5 \mathrm{~V}$ vs. $\mathrm{Li} / \mathrm{Li}^{+}$ 
leading to various fragments including $\mathrm{F}^{-}, \mathrm{PF}_{5}$ or other degraded compounds. The presence of $[\mathrm{Mn}(\mathrm{F})(\mathrm{DMC})(\mathrm{MeOH})]^{+}$at $\mathrm{m} / \mathrm{e}$ 196 serves as a further evidence that $\mathrm{PF}_{6}{ }^{-}$reacts with $\mathrm{Mn}^{2+}$ even before storage.

Storage at $55^{\circ} \mathrm{C}$ significantly accelerates these decompositions, whose ESI-MS (Fig. 2f) becomes dominated by $\mathrm{Mn}^{2+}$-solvation species, in sharp contrast with the spectra before the storage (Fig. 2e) where $\mathrm{Li}^{+}$-solvation species still prevailed. More importantly, it now display a much more complicated background pattern that reflects extensive decomposition, among which the prominent species include the Mn-containing species consisting of the fragments of electrolyte components such as $[\mathrm{MnF}(\mathrm{DMC})]^{+}(\mathrm{m} / \mathrm{e} \mathrm{164}),\left[\mathrm{MnF}(\mathrm{MeOH})_{2}\right]+(\mathrm{m} / \mathrm{e} \mathrm{137.9)}$ and $\left[\mathrm{MnF}(\mathrm{DMC})(\mathrm{MeOH})_{2}\right]^{+}(\mathrm{m} / \mathrm{e}$ 196), etc. Apparently, at this moment the bulk composition of the electrolyte is no longer what represented by the face formula of $\left[1.0 \mathrm{M} \mathrm{LiPF} \mathrm{Li}_{6+} 0.3 \mathrm{M} \mathrm{Mn}\right.$ $(\mathrm{TFSI})_{2}$ in EC/DMC]. Instead, it contains a high $\mathrm{Mn}^{2+}$-concentration accompanied by a series of decomposition products from $\mathrm{PF}_{6}{ }^{-}$anion, including $\mathrm{F}^{-}$and other fragments resulting from the carbonate molecules. Aside from liquid phase, analysis was also performed on the gaseous products resulting from the electrolyte decomposition catalyzed by $\mathrm{Mn}^{2+}$-species. Thus, Electrolytes 5 and 6 were stored in pouch bags and left at $55^{\circ} \mathrm{C}$ for 8 days, after which $\sim 0.8 \mathrm{~mL}$ of gas samples were extracted from each bag. The co-existence of $\mathrm{Mn}^{2+}$ and $\mathrm{PF}_{6}^{-}$(Electrolyte 6) apparently induced significant decomposition reactions (Supplementary Fig. 4), as evidenced not only by the numerous peaks with varying retention time, but also by the significant quantity as reflected by peak 7 . While it is impossible to accurately identify each species due to the chaotic decomposition reactions, which are further complicated by the fragmentation process in MS, we can recognize diversified F-containing species that have origin from the carbonate esters. Most importantly, the detailed analysis on the low-retention time peaks $(t<7 \mathrm{~min})$ identified a dominant species at $\mathrm{m} / \mathrm{e}=69$, which should be attributed to $\left[\mathrm{PF}_{2}\right]^{+}$, most likely originated from $\mathrm{PF}_{6}{ }^{-}$or $\mathrm{PF}_{5}$ by $\mathrm{Mn}^{2+}$ then fragmented during the bombardment in MS stage.

Differential scanning calorimetry (DSC) performed on electrolytes displays a major exothermic reaction at $64^{\circ} \mathrm{C}$ for Electrolyte 6 , which is ca. $42^{\circ} \mathrm{C}$ lower than the other two electrolytes without $\mathrm{Mn}^{2+}$ (Electrolytes 2 and 5; Fig. 2g). This process should correspond to the spontaneous decomposition reactions initialized by $\mathrm{Mn}^{2+}$ and participated by $\mathrm{PF}_{6}{ }^{-}$anion and carbonate solvents. Although most LIBs operate at ambient temperatures, it should be mentioned here that the core temperature of the spirally wound cells could easily surpass $40^{\circ} \mathrm{C}$, while high rate drain drives such temperature even higher to the neighborhood of these above exothermic onset ${ }^{23}$. In other words, the above electrolyte decompositions induced by $\mathrm{Mn}^{2+}$ could exist universally. Unfortunately, this potentially critical failure mechanism has been overlooked thus far when evaluating how Mn dissolution induces performance degradations of LIBs.

Acidity measurement provides a supplemental way to quantify how electrolytes decompose, as it was well known that HFcontent in an electrolyte is proportionate to $\mathrm{PF}_{5}$, which is more sensitive to hydrolysis by trace moisture than does $\mathrm{PF}_{6}{ }^{-}$ anion $^{24,25}$. This is exactly what Supplementary Fig. 5 indicates, i.e., high acidity arises from $\mathrm{Mn}^{2+}$-containing electrolyte after thermal storage. As the initial $\mathrm{H}_{2} \mathrm{O}$ contents of Electrolytes 5 and 6 are essentially the same within experimental error, the higher acidity of Electrolyte 6 after storage should be mainly ascribed to the decomposition of $\mathrm{PF}_{6}-$ induced by the presence of $\mathrm{Mn}^{2+}$. Meanwhile, the $\mathrm{Mn}^{2+}$-presence significantly impacted the cycling stability of the LIB, as shown in Fig. 2h (upper) and Supplementary Fig. 6, where graphite/Li half-cells were assembled using Electrolyte 6 both before and after thermal storage. The reversible lithiation/delithiation of graphite could still be supported by Electrolyte 6 before high temperature storage, despite the significant decomposition of bulk electrolyte catalyzed by $\mathrm{Mn}^{2+}$-species as represented by the event at $\sim 1.0 \mathrm{~V}$ vs. $\mathrm{Li}$ in the 1st lithiation process. This irreversible event could be more visually outstanding when overlaid with Electrolyte 5 that contains no $\mathrm{Mn}^{2+}$ (Supplementary Fig. 7), and should correspond to the electrochemical reduction of EC molecules activated in the $\mathrm{Mn}^{2+}$-solvation sheath. Thermal storage at elevated temperature further catalyzed these decomposition reactions to a point where the bulk electrolyte composition is no longer what the face formula represents, and the graphite cannot even be lithiated/de-lithiated for a single cycle now (Fig. 2h, lower). In fact, the delithiation process of graphite in Electrolyte 6 after storage displays a rather abnormally high "capacity" at a potential that positively deviates from the normal delithiation profile of graphite anode. This parasitic process was caused by the electrochemical reactivity of the side products generated by $\mathrm{Mn}^{2+}$-catalysis during the storage. Those impurities, most of which were captured by the ESI-MS for Electrolyte 6 after storage (Fig. 2f), react with both graphite anode and $\mathrm{Li}$ metal counter electrode. Especially during Li-deposition (or delithiation of graphite), the nascent Li-deposition presents a far more reactive surface on $\mathrm{Li}$ metal, inducing severe reductions. Such "asymmetry" creates a pseudo-excessive delithiation capacity as observed in Fig. 2h. Post-mortem analysis on graphite conducted by scanning electron microscope (SEM), elemental mapping and transmission electron microscope (TEM) confirm the massive electrolyte decomposition in Electrolyte 6, which leads to significant population of $\mathrm{O}$-containing species that almost completely camouflaged the presence of $\mathrm{C}$ and $\mathrm{Mn}$ on the graphite surface (Supplementary Fig. 8).

Effect of deposited Mn-species on electrolyte stability. Aside from its effect on the stability of bulk electrolyte components, $\mathrm{Mn}^{2+}$ also affects the interfacial reactions when its solvation sheath approaches the anode surface. Considering that the interaction energies of $\mathrm{Mn}^{2+}$ with both $\mathrm{EC}$ and $\mathrm{PF}_{6}-$ are much higher (more negative) than $\mathrm{Li}^{+}$, it is logical to anticipate that $\mathrm{Mn}^{2+}$-solvation sheath alters how the $\mathrm{Li}^{+}$-solvation sheath structure dictates interphasial chemistry as established previously ${ }^{26}$. Specifically, in an electrolyte where $\mathrm{PF}_{6}{ }^{-}$is the only anion, the binding between the $4^{\text {th }} \mathrm{EC}$ solvent and $\left[\mathrm{Mn}^{2+}\right.$ (EC) $\left.{ }_{3} \mathrm{PF}_{6}^{-}\right]$or between $\mathrm{PF}_{6}^{-}$and $\left[\mathrm{Mn}^{2+}(\mathrm{EC})_{4}\right]$ is much stronger than those between $\mathrm{EC}$ and $\left[\mathrm{Li}^{+} \mathrm{PF}_{6}{ }^{-}\right]$ion-pair or $\mathrm{PF}_{6}^{-}$and $\left[\mathrm{Li}^{+}(\mathrm{EC})\right]$ (Fig. 3a, b). Hence a $\mathrm{Mn}^{2+}$-solvation sheath would be much more difficult to desolvate than a $\mathrm{Li}^{+}$-solvation sheath. As consequence, the "kidnaped" anion may very likely be brought to the anode surface by $\mathrm{Mn}^{2+}$ and experience the low potential there. This would significantly raise the opportunity of anionreduction and introduction of anion-originated species as part of the new interphase. The one-electron reduction activity of $\mathrm{Li}^{+}$ and $\mathrm{Mn}^{2+}$ solvation sheaths with and without $\mathrm{PF}_{6}{ }^{-}$anion were thus compared in Fig. 3c, d. The optimized structure of $\mathrm{Mn}^{2+}$ solvation sheaths before and after one electron reduction were shown in Supplementary Fig. 9, with the structures of $\mathrm{Li}^{+}$solvation sheath already reported in our previous work ${ }^{26}$. The electron affinity energy of $\mathrm{Mn}^{2+}$-solvation sheath is found to be significantly higher (negative) than that of $\mathrm{Li}^{+}$-solvation sheath, indicating the former $\left(\mathrm{Mn}^{2+}\right)$ should be the winner in the competition for electron from anode surface over the latter $\left(\mathrm{Li}^{+}\right)$, in good agreement with the conclusion drawn earlier that $\mathrm{Mn}^{2+}$. presence in electrolyte accelerates the electrolyte reduction ${ }^{27}$.

Interestingly, for a $\mathrm{Mn}^{2+}$-solvation sheath without $\mathrm{PF}_{6}{ }^{-}$, the gained electron prefers to associate with EC molecule instead of 

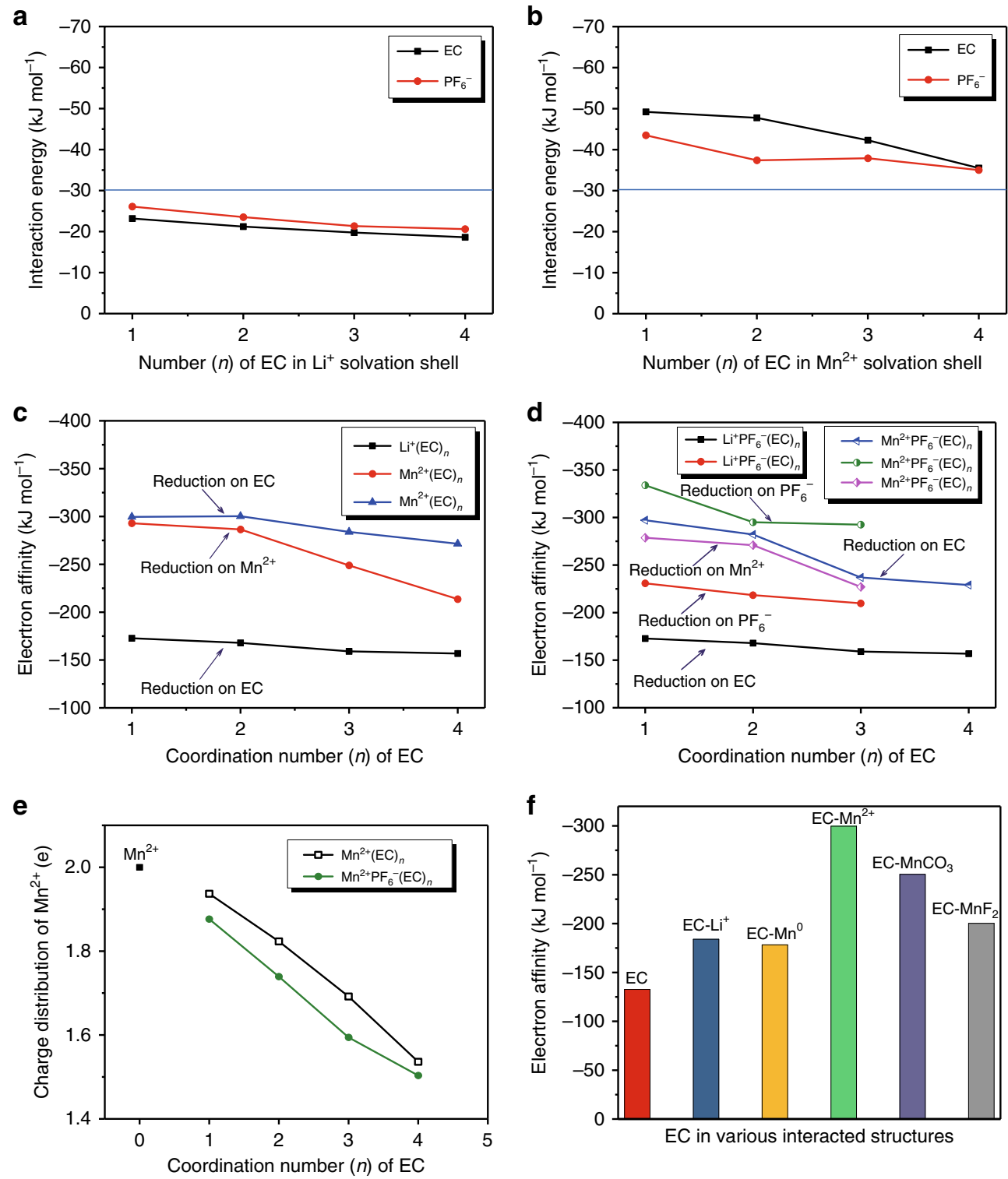

Fig. 3 Interaction energy and reduction activity of $\mathrm{Mn}^{2+}$ species. Interaction energy of $\mathrm{EC}$ solvent and $\mathrm{PF}_{6}-$ with $\mathrm{Li}^{+}$(a) and $\mathrm{Mn}^{2+}(\mathbf{b})$; Electron affinity energy of $\mathrm{Li}^{+}$and $\mathrm{Mn}^{2+}$ solvation shells with (c) and without (d) $\mathrm{PF}_{6}{ }^{-}$; Charge distribution of $\mathrm{Mn}^{2+}$ in solvation shells (e); Electron affinity energy of EC in various interacted structures (f)

occupying the $3 \mathrm{~d}$ orbital of $\mathrm{Mn}^{2+}$ (Fig. 3c), implying that EC will be preferentially reduced over $\mathrm{Mn}^{2+}$. If the $\mathrm{Mn}^{2+}$ solvation sheath contains $\mathrm{PF}_{6}{ }^{-}$, however, the gained electron prefers to associate with $\mathrm{PF}_{6}-$ (Fig. $3 \mathrm{~d}$ ), leading to a series of fluorides $\left[\mathrm{PF}_{5}\right.$ and $(\mathrm{MnF})^{+}$, which are even more reactive toward carbonate molecules than the salt anion itself. Considering that both types of $\mathrm{Mn}^{2+}$-solvation sheaths coexist as evidenced by ESI-MS data (Fig. 2e, f), the above processes should proceed simultaneously. In either case, the reductive pathway of $\mathrm{Mn}^{2+}$-species on anode surface does not generate $\mathrm{Mn}^{0}$, but instead catalyzes the reduction of the solvating members within the $\mathrm{Mn}^{2+}$-solvation sheath, be it carbonate molecules or anion. This conclusion agrees with the recent observations by $\mathrm{Lu}$ et al. and Jarry et al. respectively that TM cations retain their oxidation state on anode surface ${ }^{28-30}$, and directly rectifies the early belief that they will be reduced into elemental form on anode surface because of their higher redox potential (e.g., $\mathrm{Mn} / \mathrm{Mn}^{2+}$ at $1.87 \mathrm{~V}$ vs. $\left.\mathrm{Li} / \mathrm{Li}^{+}\right)^{4,27}$. We believe that this early misconception might have arisen because the critical role of solvation sheath was overlooked. As in the scenarios displayed by $\mathrm{Xu}$ and coworkers for $\mathrm{Li}^{+}$, these solvation sheaths serve as molecular-sized reaction vessels, in which the central cation activates their solvation member and directs how the reaction should proceed. Only when the solvation sheath starts to lose solvating members could the reduction of $\mathrm{Mn}^{2+}$ become possible (Fig. 3c), where the electron affinity energy of $\mathrm{Mn}^{2+}$ eventually approaches that of EC with decreasing solvation number. Hence the opportunity of $\mathrm{Mn}^{2+}$ reduction cannot be completely ruled out when anode potential is driven under certain threshold values, where strong electric field would strip $\mathrm{Mn}^{2+}$ off any solvent molecules or anions, and the low potential will force $\mathrm{Mn}^{2+}$ to reduce. This explains why metallic Mn was rarely detected on graphite surface, but occasionally evidences were still presented for their existence ${ }^{31-33}$. Alternative twoelectron pathway was also considered, where the reduction activity and reduction structures of $\mathrm{Mn}^{2+}$ solvation sheath, in presence and absence of $\mathrm{PF}_{6}^{-}$, were shown in Supplementary Figs. 10 and 11. It can be further noted that the electron affinity energy of $\mathrm{Mn}^{2+}$ reduction is always lower (less negative) in 
comparison with the reductions of $\mathrm{EC}$ and $\mathrm{PF}_{6}{ }^{-}$in a solvation sheath, indicating that the possibility of $\mathrm{Mn}^{2+}$ to receive two electrons is even less likely than the scenario of one-electron reduction of $\mathrm{Mn}^{2+}$ (Fig. 3c, d). Similarly, reduction of $\mathrm{PF}_{6}{ }^{-}$anion remains the most thermodynamically favorable reaction.

To further examine the previous belief that TM particles in elemental form $\left(\mathrm{Mn}^{0}\right)$ catalyze the reduction of carbonate molecules on electrode surface, the ability of $\mathrm{Mn}^{0}$ and $\mathrm{Mn}^{2+}$ in activating EC for reduction is compared (Fig. 3f), with the corresponding optimized structures shown in Supplementary Fig. 12. The electron affinity of EC- $\mathrm{Mn}^{2+}$ is obviously higher (more negative) than other investigated complexes, $\mathrm{Mn}^{0}$ in particular, which implies that $\mathrm{Mn}^{2+}$ is more effective in inducing electrons from the anode and then mediate it to carbonate molecules for reduction. This should be apparently attributed to the stronger electron-withdrawing capability of $\mathrm{Mn}^{2+}$ than $\mathrm{Mn}^{0}$. The electron affinity of EC- $\mathrm{Mn}^{0}$, though, is still higher than the neat EC solvent, therefore the existence of metallic Mn indeed would activate EC for reduction, but should not constitute the major contribution when $\mathrm{Mn}^{2+}$ is present.

The similar trend can be derived from the energy profiles of EC decomposition in the absences or presences of $\mathrm{Li}^{+}, \mathrm{Mn}^{0}$, and $\mathrm{Mn}^{2+}$ (Fig. 4), respectively, with the optimized structures shown in Supplementary Figs. 13 and 14. The existence of $\mathrm{Mn}^{0}$ significantly lowers the EC decomposition activation energy (Fig. 4a) from 247.20 (TS1) to 33.69 (TS3) $\mathrm{kJ} \mathrm{mol}^{-1}$. Interestingly, the decomposition activation energy of EC coordinated with $\mathrm{Mn}^{2+}$ (TS7) is lower than that of neat EC (TS1) by only $16.57 \mathrm{~kJ}$ $\mathrm{mol}^{-1}$. On the other hand, once receiving one electron, the reduced form of EC decomposition (TS10) becomes significantly easier than EC (TS1) before reduction. In consideration of the strong catalytic effect of $\mathrm{Mn}^{2+}$ on EC reduction (Fig. 3f), the reduced form of EC may dissociate from $\mathrm{Mn}^{2+}$ and then proceed with further cascade of decomposition (TS10) without $\mathrm{Mn}^{2+}$. The decomposition activation energy of reduced EC with $\mathrm{Mn}^{2+}$ (TS21) is about $9 \mathrm{~kJ} \mathrm{~mol}^{-1}$ higher than that of reduced EC (TS10), again indicating that after being receiving one electron, EC anion would dissociate from $\mathrm{Mn}^{2+}$. The leaving EC molecule would leave a coordination vacancy near $\mathrm{Mn}^{2+}$ for other incoming EC molecules. In an overall picture of the entire catalytic process (Fig. $4 \mathrm{c}$ ), the $\mathrm{Mn}^{2+}$-solvation sheath, no matter in bulk electrolyte or on electrode surface, acts as the catalytic center, which continuously activates the carbonate molecules for reduction, leading to incessant electrolyte consumption and cell degradation. On atomic level, one would expect that such activation of solvation sheath members by the center TM cation should be directly related to the specific d-electron configuration of the latter. This realization carries significant importance to the understanding of the electrolyte destabilization mechanisms, and should be further explored.

Finally, it should be cautioned that the Mn-content deliberately added in this work is higher than an electrolyte could experience in actual battery, hence the effect of Mn-catalysis may have been exaggerated. However, for system of extreme complexity such as the electrolyte decomposition, exaggeration more often than not brings necessary simplicity that serves as starting point to derive a model that can be further perfected. The mechanism and fundamental understanding achieved in this work therefore help shed initial light on an issue that was under-investigated because of its difficulty.

\section{Discussion}

We demonstrated in this work that, besides interfacial Mn-species, the once overlooked $\mathrm{Mn}^{2+}$ in bulk electrolyte solution significantly contributes to destabilize the carbonate-based electrolytes. In comparison with $\mathrm{Li}^{+}$, the bivalent $\mathrm{Mn}^{2+}$ generates larger solvation sheath containing both $\mathrm{PF}_{6}{ }^{-}$and carbonate molecules, with cyclic EC preferred over acyclic DMC. Within such intimate distance confined by the solvation sheath, $\mathrm{Mn}^{2+}$ readily destabilizes both carbonate molecules and anion, either for side reactions in the bulk or for electrochemical reduction at anode surface. The destabilization of bulk electrolyte become rather pronounced at elevated temperatures, which could have significantly changed the bulk electrolyte composition. In particular, at the anode surface, $\mathrm{Mn}^{2+}$-solvation sheath activates its solvating members (carbonate molecule, anion) for reduction,
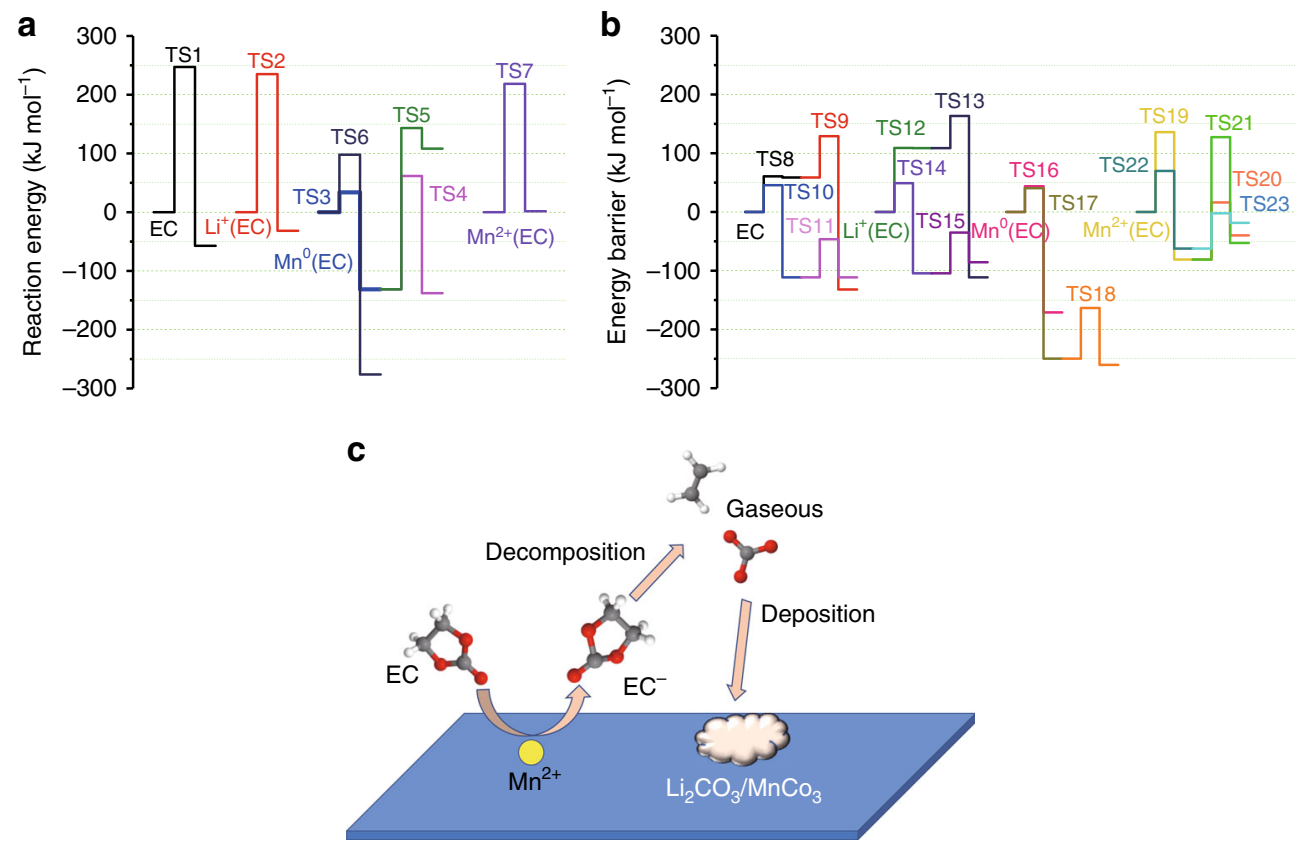

Fig. 4 Influence of $\mathrm{Mn}^{2+}$ species on the decomposition mechanism of electrolyte. Decomposition reaction profiles of EC with and without interacting with $\mathrm{Li}^{+}$, metallic $\mathrm{Mn}$ and $\mathrm{Mn}^{2+}$ before (a) and after one electron reduction (b) from DFT calculation; Catalytic mechanism of $\mathrm{Mn}^{2+}$ on the reduction decomposition of electrolytes (c) 
rather than being reduced into $\mathrm{Mn}^{0}$. The presence of $\mathrm{Mn}^{2+}$ in bulk electrolyte or on anode surface serves as catalytic centers that induce continuous electrolyte consumption at the expense of the cell performances.

\section{Methods \\ Molecular dynamic simulations. The electrolyte was modeled with the non- polarizable force-field from refs. ${ }^{34,35}$ for $\mathrm{Li}^{+}, \mathrm{PF}_{6}{ }^{-}, \mathrm{EC}, \mathrm{DMC}$, and $\mathrm{TFSI}^{-}$, and Bradbrook et al. ${ }^{36}$ for $\mathrm{Mn}^{2+}$. The starting configurations were prepared utilizing $\mathrm{fftool}^{37}$ and packmol ${ }^{38}$. The initial setup electrolytes were equilibrated at $393 \mathrm{~K}$ and $1 \mathrm{~atm}$ for $2 \mathrm{~ns}$ in NPT ensemble. The production runs were generated in NVT ensemble at $393 \mathrm{~K}$ and had a length of $168.4 \mathrm{~ns}$ for the system with $\mathrm{Mn}^{2+}$ and $20 \mathrm{~ns}$ for simulations without $\mathrm{Mn}^{2+}$. Nose Hoover thermostat was adopted to control the temperature ${ }^{39}$ having a coupling constant of $200 \mathrm{fs}$. The van der Waals and real space Ewald short-range interactions were calculated within a $12 \AA$ spherical cut off. The electrostatic interactions were calculated utilizing Ewald method ${ }^{40}$ and particle mesh scheme $\mathrm{e}^{41}$ for the reciprocal part. The coordination numbers around ions were calculated at the following distances (encompassing most of the first peak in rdf) ion- $\mathrm{O}=2.4 \AA$, ion- $\mathrm{P}=4.4 \AA$, ion- $\mathrm{F}=2.8 \AA$. \\ The simulation cell was cubic and had $3 \mathrm{D}$ periodicity. The simulated systems consisted of 306 molecules of DMC and 312 molecules of EC (1:1 weight ratio), 48 ionic pairs of $\mathrm{LiPF}_{6}$ and 6 ionic pairs of $\mathrm{Mn}(\mathrm{TFSI})_{2}$.}

Density functional theory calculations. All DFT calculations were performed with the Gaussian 09 software $^{42}$. B3LYP/6-311++G (d) method was adopted to optimize the investigated solvents and complexes ${ }^{26,43}$. Frequency analysis was applied with the same method to verify that each obtained optimized structure was at the energy minimum point. The energy shown in this work were calculated at 298.15 K. Solvent effects were considered with the application of polarized continuum models using a dielectric constant of 20.5 (Acetone solvent). Charge distributions were analyzed by nature population analysis according to natural bond orbital (NBO) theory. $3 d^{5}$ was chosen as the outmost electrons in DFT calculation for $\mathrm{Mn}^{2+}$.

Sample preparation. Battery-grade ethylene carbonate (EC), dimethyl carbonate (DMC) and lithium hexafluorophosphate $\left(\mathrm{LiPF}_{6}\right)$ were provided by Guangzhou Tinci Materials Technology Co. Ltd., China. Lithium bis(trifluoromethanesulfonyl) imide (LiTFSI) (99\%) and manganese (II) bis(trifluoromethanesulfonyl)imide (Mn $\left.(\mathrm{TFSI})_{2}\right)(>98 \%)$ were provided by Aladdin. The above electrolyte components were used without further refinement. A base solvent, EC/DMC (1/1 in weight) was formulated. 1.0 $\mathrm{M} \mathrm{LiPF}_{6}, 0.6 \mathrm{M}$ LiTFSI, $0.3 \mathrm{M} \mathrm{Mn}(\mathrm{TFSI})_{2}$, [1.0 $\mathrm{M} \mathrm{LiPF}_{6}+0.6 \mathrm{M}$ LiTFSI] and $\left[1.0 \mathrm{M} \mathrm{LiPF}_{6}+0.3 \mathrm{M} \mathrm{Mn}(\mathrm{TFSI})_{2}\right]$ were applied in the base solvent to obtain electrolyte of $2,3,4,5$, and 6 respectively, see Supplementary Table 1 . The preparation of the electrolyte is carried out in the glove box (MBraun, Germany) filled with argon, in which the $\mathrm{O}_{2}$ and $\mathrm{H}_{2} \mathrm{O}$ contents were lower than 10 and 0.1 ppm, respectively. The $\mathrm{H}_{2} \mathrm{O}$ content of electrolytes were measured by Karl-Fisher 798 GPT Titrino (Metrohm, Switzerland). The $\mathrm{H}_{2} \mathrm{O}$ content shown in this paper were the average of three parallel tests.

The injection of 1000 ppm HF, whose effect was shown in Supplementary Fig. 3, was prepared in two steps. At first $2.1 \mathrm{~mL} 20 \mathrm{M} \mathrm{L}^{-1} \mathrm{HF}$ solution was injected into $40 \mathrm{~mL}$ Electrolyte 1 to obtain HF-containing baseline. Then $3 \mu \mathrm{L}$ HF-containing baseline was respectively injected into $3 \mathrm{~mL}$ Electrolytes 1, 2, 3, 4, 5, and 6 to obtain the samples with $1000 \mathrm{ppm}$ HF.

Graphite slurry was obtained by mixing artificial graphite ( $80 \mathrm{wt} \%$, offered by Dongguan Kaijin New Energy Technology Co., Ltd, China), acetylene carbon black (10 wt\%) and poly(vinylidene fluoride; $10 \mathrm{wt} \%$ ) in $N$-methyl-pyrrolidone. The above slurry was then coated on $\mathrm{Cu}$ current collector and dried at 80 and $120^{\circ} \mathrm{C}$ for 2 and $12 \mathrm{~h}$ in vacuum drying oven, respectively, to obtain graphite electrode. The graphite electrode was rolled before used. Lithium plate was used as counter and reference electrode in CR2025-type graphite/Li half-cells with Celgard 2400 membrane separator. Cell assembly was completed in the glove box.

Electrolyte storage. The prepared electrolytes were initially stored in polyethylene bottles sealed with an air-tight lid, which was further sealed with teflon tape and cellophane tape to ensure the good sealing (see Supplementary Fig. 15). This sealing has been adopted by some electrolyte companies when shipping solvents and electrolytes. The polyethylene bottles were transferred subsequently to the vacuum dryer for storage. After 8 days of storage at high temperature, the plastic bottles were transferred to the glove box again. And the stored electrolytes were finally transferred into glass bottles for photograph because the polyethylene bottles are opaque.

To further verify the airtightness/moisture-exclusiveness of the plastic bottles and sealing, we measured the $\mathrm{H}_{2} \mathrm{O}$ content of electrolyte 1 (solvents only, with no influence from salts) before and after 8-day storage in the vacuum dryer, which turned out to be 20 and $21 \mathrm{ppm}$, respectively, confirming that the manner that electrolytes are sealed and stored could effectively exclude the permeation of moisture from ambient.
Electrochemical measurements. The room-temperature cyclic stability of $\mathrm{Li} /$ graphite half-cells were tested between 0.005 and $2.5 \mathrm{~V}$ with LAND system (CT2001A, Wuhan, China). After 3 cycles of activation at $0.1 \mathrm{C}$, the Li/graphite half-cells were performed at $0.2 \mathrm{C}\left(1 \mathrm{C}=372.6 \mathrm{~mA} \mathrm{~g}^{-1}\right)$ for the subsequent cycles.

Physical characterization. The electrospray ionization mass spectrometries (ESIMS) of electrolyte before and after storage at $55^{\circ} \mathrm{C}$ were executed on TSQ Quantum Ultra. The spray voltage was $+3 \mathrm{kv}$ while the capillary temperature was $300^{\circ} \mathrm{C}$. The sheath gas and aux gas flow rates were 30 and 5 arb, respectively. Methanol was used as a co-solvent during the ESI-MS characterization. The date ranging from $\mathrm{m} / \mathrm{e}=50-1000$, were available. Thermal stability of electrolytes in the temperature range of $25-300^{\circ} \mathrm{C}$ was investigated using differential scanning calorimeter (DSC, PerkinElmer DSC 4000 , Hetherlands) with $10^{\circ} \mathrm{C} \mathrm{min}-1$ heating rate.

Ex-situ scanning electron microscope (SEM) and transmission electron microscope (TEM) characterization were performed on JEOL-5900 SEM and JEM$2100 \mathrm{HR}$ (Japan), respectively. All electrode samples were vacuum transferred to the test equipment. The acidity of electrolytes after storage were measured by precise $\mathrm{PH}$ test papers (PH:1.4-3.0, Q/GHSC) which were provided by Shanghai SSS Reagent CO. LTD, Shanghai China. Gaseous products of electrolyte decomposition during storage were investigated by Gas chromatography mass spectrometry (GC MS) QP2010 Ultra Shimadzu. Approximately $10 \mathrm{~mL}$ Electrolytes 5 and 6 were stored in pouch bags made from the same foil materials used to assemble pouch cells (see Supplementary Fig. 16).

After 8-day storage at $55^{\circ} \mathrm{C}, \sim 0.8 \mathrm{~mL}$ gas sample was extracted from the bags with a syringe through the pre-installed valves and then injected into a DB-5 capillary column $(30 \mathrm{~m} \times 0.25 \mathrm{~mm}$ inner diameter, $0.25 \mu \mathrm{m}$ film thickness). Carrier gas, Helium, was used at a flow rate of $1.47 \mathrm{~mL} \mathrm{~min}^{-1}$. The inlet temperature was $150{ }^{\circ} \mathrm{C}$, while the column temperature was initially set at $30^{\circ} \mathrm{C}$ for 10 mins, then increased to $150{ }^{\circ} \mathrm{C}$ with $10{ }^{\circ} \mathrm{C} \mathrm{min}-1$ and maintained for another 5 mins. The mass spectrometer was operated with electron impact $(\mathrm{EI})$ mode $(0.1 \mathrm{kV})$ at the rate of $1250 \mathrm{amu} \mathrm{s}^{-1}$. Full-scan mass spectra were obtained from 20 to $100 \mathrm{~m} / \mathrm{e}$. The MS results were shown in Supplementary Fig. 4.

\section{Data availability}

The authors declare that the main data supporting the findings of this study are available within the article and its Supplementary Information files. Extra data are available from the corresponding author upon request.

\section{Code availability}

The molecular dynamic simulations were run utilizing the LAMMPS ${ }^{44}$ general purpose open-source code, and according to LAMMPS website https://lammps.sandia.gov, "LAMMPS is distributed as an open source code under the terms of the GPL". The code LAMMPS can be downloaded from: https://lammps.sandia.gov/download.html.

Received: 25 January 2019 Accepted: 13 July 2019

Published online: 31 July 2019

\section{References}

1. Tarascon, J. M. \& Armand, M. Issues and challenges facing rechargeable lithium batteries. Nature 414, 359-567 (2001).

2. Armand, M. \& Tarascon, J. M. Buliding better batteries. Nature 451, 652-657 (2008).

3. Lee, J. et al. Reversible $\mathrm{Mn}^{2+} / \mathrm{Mn}^{4+}$ double redox in lithium-excess cathode materials. Nature 556, 185-190 (2018).

4. Komaba, S., Kumagai, N. \& Kataoka, Y. Influence of manganese(II), cobalt(II) and nickel(II) additives in electrolyte on performance of graphite anode for lithium-ion batteries. Electrochim. Acta 47, 1229-1239 (2002).

5. Wang, X. Q., Nakamura, H. \& Yoshio, M. Capacity fading mechanism for oxygen defect spinel as a $4 \mathrm{~V}$ cathode material in Li-ion batteries. J. Power Sources 110, 19-26 (2002).

6. Xia, Y. Y., Zhou, Y. H. \& Yoshio, M. Capacity fading on cycling of $4 \mathrm{~V} \mathrm{Li/}$ $\mathrm{LiMn}_{2} \mathrm{O}_{4}$ cells. J. Electrochem. Soc. 144, 2593-2600 (1997).

7. Park, S. C. et al. The elevated temperature performance of $\mathrm{LiMn}_{2} \mathrm{O}_{4}$ coated with $\mathrm{LiNi}_{1-x} \mathrm{Co}_{x} \mathrm{O}_{2}(x=0.2$ and 1). J. Power Sources 107, 42-47 (2002).

8. Tsunekawa, H. et al. Capacity fading of graphite electrodes due to the deposition of manganese ions on them in Li-ion batteries. J. Electrochem. Soc 149, A1326-A1331 (2002)

9. Komaba, S. et al. Impact of 2-Vinylpyridine as electrolyte additive on surface and electrochemistry of graphite for $\mathrm{C} / \mathrm{LiMn}_{2} \mathrm{O}_{4} \mathrm{Li}$-ion cells. J. Electrochem. Soc. 152, A937-A946 (2005).

10. Cho, I. H., Kim, S. S., Shin, S. C. \& Choi, N. S. Effect of SEI on capacity losses of spinel lithium manganese oxide/graphite batteries stored at $60^{\circ} \mathrm{C}$. Electrochem. Solid State Lett. 13, A168-A172 (2010). 
11. Deng, B. H., Nakamura, H. \& Yoshio, M. Capacity fading with oxygen loss for manganese spinels upon cycling at elevated temperatures. J. Power Sources 180, 864-868 (2008).

12. Lu, J. et al. Effectively suppressing dissolution of manganese from spinel lithium manganate via a nanoscale surface-doping approach. Nat. Commun. 5, 5693 (2014).

13. Norberg, N. S., Lux, S. F. \& Kostecki, R. Interfacial side-reactions at a $\mathrm{LiNi}_{0.5} \mathrm{Mn}_{1.5} \mathrm{O}_{4}$ electrode in organic carbonate-based electrolytes. Electrochem. Commun. 34, 29-32 (2013).

14. Zheng, Q. F. et al. N-Allyl-N,N-Bis(trimethylsilyl)amine as a novel electrolyte additive to enhance the interfacial stability of a Ni-rich electrode for Lithiumion batteries. ACS Appl. Mater. Interfaces 10, 16843-16851 (2018).

15. Wang, K. et al. A comparative study of Si-containing electrolyte additives for lithium ion battery: which one is better and why is it better. J. Power Sources 342, 677-684 (2017).

16. $\mathrm{Li}, \mathrm{J} . \mathrm{H}$. et al. Improving high voltage interfacial and structural stability of layered Lithium-rich oxide cathode by using a boracic electrolyte additive. $J$. Electrochem. Soc. 163, A2258-A2264 (2016).

17. Wang, Z. S., Xing, L. D., Li, J. H., Xu, M. Q. \& Li, W. S. Triethylborate as an electrolyte additive for high voltage layered lithium nickel cobalt manganese oxide cathode of lithium ion battery. J. Power Sources 307, 587-592 (2016).

18. von Cresce, A. \& Xu, Kang Preferential solvation of $\mathrm{Li}^{+}$directs formation of interphase on graphitic anode. Electrochem. Solid State Lett. 14, A154-A156 (2011).

19. von Wald Cresce, A., Borodin, O. \& Xu, K. Correlating $\mathrm{Li}^{+}$solvation sheath structure with interphasial chemistry on graphite. J. Phys. Chem. C 116, 26111-26117 (2012).

20. $\mathrm{Xu}, \mathrm{K}$. Nonaqueous liquid electrolytes for Lithium-based rechargeable batteries. Chem. Rev. 10, 4303-4418 (2004).

21. Gnanaraj, J. S., Zinigrad, E., Levi, M. D., Aurbach, D. \& Schmidt, M. A comparison among $\mathrm{LiPF}_{6}, \mathrm{LiPF}_{3}\left(\mathrm{CF}_{2} \mathrm{CF}_{3}\right)_{3}(\mathrm{LiFAP})$, and $\mathrm{LiN}\left(\mathrm{SO}_{2} \mathrm{CF}_{2} \mathrm{CF}_{3}\right)_{2}$ (LiBETI) solutions: electrochemical and thermal studies. J. Power Sources 119, 799-804 (2003).

22. Xu, M. Q. et al. Experimental and theoretical investigation of dimethyl acetamide (DMAc) as electrolyte stabilizing additive for lithium ion batteries. J. Phys. Chem. C 115, 6085-6094 (2011).

23. Song, L. B. et al. Thermal behaviors study of $\mathrm{LiFePO}_{4}$ cell by electrochemicalcalorimetric method. Electrochim. Acta 90, 461-467 (2013).

24. Heider, U., Oesten, R. \& Jungnitz, M. Challenge in manufacturing electrolyte solutions for lithium and lithium ion batteries quality control and minimizing contamination level. J. Power Sources 81, 119-122 (1999).

25. Aurbach, D. et al. Recent studies on the correlation between surface chemistry, morphology, three-dimensional structures and performance of $\mathrm{Li}$ and $\mathrm{Li}-\mathrm{C}$ intercalation anodes in several important electrolyte systems. J. Power Sources 68, 91-98 (1997).

26. Xing, L. D. et al. Deciphering the ethylene carbonate-propylene carbonate mystery in Li-ion batteries. Acc. Chem. Res. 51, 282-289 (2018).

27. Solchenbach, S., Gloria Hong, G., Freiberg, A. T. S., Jung, R. \& Gasteiger, H. A. Electrolyte and SEI decomposition reactions of transition metal ions investigated by on-line electrochemical mass spectrometry. J. Electrochem. Soc. 165, A3304-A3312 (2018).

28. Zhan, C. et al. Mn(II) deposition on anodes and its effects on capacity fade in spinel lithium manganate-carbon systems. Nat. Commun. 4, 2437 (2013).

29. Zhan, C., Qiu, X. P., Lu, J. \& Amine, K. Tuning the Mn deposition on the anode to improve the cycle performance of the Mn-based Lithium ion battery. Adv. Mater. Interfaces 3, 1500856 (2016).

30. Jarry, A. et al. The formation mechanism of fluorescent metal complexes at the $\mathrm{Li}_{\mathrm{X}} \mathrm{Ni}_{0.5} \mathrm{Mn}_{1.5} \mathrm{O}_{4-\delta} /$ carbonate ester electrolyte interface. J. Am. Chem. Soc. 10, 3533-3539 (2015).

31. Xiao, X. C. et al. Unraveling manganese dissolution/deposition mechanisms on the negative electrode in lithium ion batteries. Phys. Chem. Chem. Phys. 16, 10398-10402 (2014).

32. Gowda, S. R. et al. Oxidation state of cross-over manganese species on the graphite electrode of lithium-ion cells. Phys. Chem. Chem. Phys. 16, 6898-6902 (2014).

33. Wandt, J. et al. Transition metal dissolution and deposition in Li ion batteries investigated by operando X-ray absorption spectroscopy. J. Mater. Chem. A 4, 18300-18305 (2016).

34. Tenney, C. M. \& Cygan, R. T. Analysis of molecular clusters in simulations of lithium-ion battery electrolytes. J. Phys. Chem. C 117, 24673-24684 (2013).

35. Kelkar, M. S. \& Maginn, E. J. Effect of temperature and water content on the shear viscosity of the ionic liquid 1-ethyl-3-methylimidazolium bis (trifluoromethanesulfonyl) imide as studied by atomistic simulations. J. Phys. Chem. B 111, 4867-4876 (2007).

36. Bradbrook, G. M. et al. X-Ray and molecular dynamics studies of concanavalin-a glucoside and mannoside complexes relating structure to thermodynamics of binding. J. Chem. Soc. Faraday Trans. 94, 1603-1611 (1998).

37. Pádua, A. A. H. Resolving dispersion and induction components for polarizable molecular simulations of ionic liquids. J. Chem. Phys. 146, 204501 (2017).

38. Martínez, L., Andrade, R., Birgin, E. G. \& Martínez, J. M. PACKMOL: a package for building initial configurations for molecular dynamics simulations. J. Comp. Chem. 30, 2157 (2009).

39. Hoover, W. G. Canonical dynamics: equilibrium phase-space distributions. Phys. Rev. A 31, 1695-1697 (1985).

40. Ewald, P. P. The Computation of optical and electrostatic lattice potentials. Ann. Phys. 369, 253 (1921).

41. Essmann, U. et al. A smooth particle mesh ewald method. J. Chem. Phys. 103, 8577-8593 (1995).

42. Gaussian 09 (Gaussian, Inc., Wallingford, CT, 2009).

43. Zhi, H. Z., Xing, L. D., Zheng, X. W., Xu, K. \& Li, W. S. Understanding how nitriles stabilize electrolyte/electrode interface at high voltage. J. Phys. Chem. Lett. 8, 6048-6052 (2017).

44. Plimpton, S. Fast parallel algorithms for short-range molecular dynamics. J. Comp. Phys. 117, 1-19 (1995).

\section{Acknowledgements}

This work is supported by the National Natural Science Foundation of China (21573080), the Guangdong Program for Support of Top-notch Young Professionals (2015TQ01N870) and the Natural Science Foundation for Distinguished Young Scholars of Guangdong Province (Grant No. 2017B030306013).

\section{Author contributions}

L.X. conceived the idea and designed experiments. W.L., L.X., and K.X. analyzed results and wrote the manuscript. C.W. performed DFT calculations and electrochemical analysis. J.V. and L.X. performed molecular dynamics simulations and analysis. Z.C. and G. L. assisted with cell assembly and physical characterizations.

\section{Additional information}

Supplementary Information accompanies this paper at https://doi.org/10.1038/s41467 019-11439-8.

Competing interests: The authors declare no competing interests.

Reprints and permission information is available online at http://npg.nature.com/ reprintsandpermissions/

Peer review information: Nature Communications thanks Nicholas Faenza and other anonymous reviewer(s) for their contribution to the peer review of this work

Publisher's note: Springer Nature remains neutral with regard to jurisdictional claims in published maps and institutional affiliations.

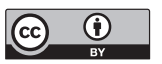

Open Access This article is licensed under a Creative Commons Attribution 4.0 International License, which permits use, sharing, adaptation, distribution and reproduction in any medium or format, as long as you give appropriate credit to the original author(s) and the source, provide a link to the Creative Commons license, and indicate if changes were made. The images or other third party material in this article are included in the article's Creative Commons license, unless indicated otherwise in a credit line to the material. If material is not included in the article's Creative Commons license and your intended use is not permitted by statutory regulation or exceeds the permitted use, you will need to obtain permission directly from the copyright holder. To view a copy of this license, visit http://creativecommons.org/ licenses/by/4.0/.

This is a U.S. Government work and not under copyright protection in the US; foreign copyright protection may apply 2019 